\title{
Psychopathological symptoms in individuals at risk of Internet addiction in the context of selected demographic factors
}

\author{
Emilia Potembska',A-F, Beata Pawłowska ${ }^{2, A-F}$, Jolanta Szymańska ${ }^{3, A-F}$ \\ ${ }^{1}$ Department of Psychiatric Nursing, Medical University, Lublin, Poland \\ 2 2nd Department of Psychiatry and Psychiatric Rehabilitation, Medical University, Lublin, Poland \\ ${ }^{3}$ Chair and Department of Paedodontics, Medical University, Lublin, Poland \\ A - Research concept and design, B - Collection and/or assembly of data, C - Data analysis and interpretation, \\ $D$ - Writing the article, E-Critical revision of the article, F-Final approval of article
}

\begin{abstract}
Potembska E, Pawłowska B, Szymańska J. Psychopathological symptoms in individuals at risk of Internet addiction in the context of selected
\end{abstract} demographic factors. Ann Agric Environ Med. 2019; 26(1): 33-38. doi: 10.26444/aaem/81665

\begin{abstract}
Introduction. Researchers who study the problems of Internet addiction point out that this dependence is often co-morbid with symptoms of a variety of pathological disorders, including anxiety, depressive, somatization, and obsessive-compulsive disorders. The goal of this study was to compare the severity of psychopathological symptoms in individuals at risk of Internet addiction (according to Young's criteria) and those not at risk of developing this addiction with respect to gender and place of residence (urban vs. rural).

Materials and method. The study included a group of 692 respondents ( 485 females and 207 males). The average age of the participants was 20.8 years. $56.06 \%$ of them lived in urban areas and $43.94 \%$ in rural areas. The following instruments were used: a sociodemographic questionnaire designed by the authors, Young's 20 -item Internet Addiction Test (IAT, Polish translation by Majchrzak and Ogińska-Bulik), and the "O" Symptom Checklist (Kwestionariusz Objawowy "O", in Polish) by Aleksandrowicz.

Results. Individuals at risk of Internet addiction showed significantly more severe pathological symptoms than the individuals who were not at risk of this addiction. There were differences in the severity of psychopathological symptoms between people at risk of Internet dependence living in urban and rural areas.

Conclusions. Individuals at risk of Internet addiction were found to be characterized by a significantly higher severity of obsessive-compulsive, conversion, anxiety, and depressive symptoms. Persons at risk of Internet addiction who lived in rural areas had significantly more severe psychopathological symptoms, mainly obsessive-compulsive, hypochondriac and phobic, compared to their urban peers.
\end{abstract}

\section{Key words}

psychopathological symptoms, Internet addiction, anxiety, depression, obsessive-compulsive disorder, gender, rural, urban

\section{INTRODUCTION}

The literature offers numerous reports on the co-morbidity of Internet addiction and risk of Internet addiction with anxiety, depressive, somatization, and obsessive-compulsive disorders [1-13]. Yen et al. [14] believe that 3 scenarios are possible:

1) psychopathological symptoms may lead to the development of Internet addiction or perpetuate existing addiction;

2) Internet addiction may lead to psychopathological symptoms;

3) psychopathological symptoms and Internet addiction may reinforce one another.

Xiuqin et al. [1] report that young people who are dependent on the Internet, compared to their non-dependent peers, have increased symptoms of depression, anxiety and obsessivecompulsive disorder. Chele et al. [12] have demonstrated that $25 \%$ of Internet dependent adolescents struggle with some level of depression, $16 \%$ have symptoms of social phobia, $12 \%$ suffer from anxiety disorder, 6\% show obsessive-compulsive

Address for correspondence: Emilia Potembska, Department of Psychiatric Nursing Medical University of Lublin, Poland, Aleje Racławickie 1, 20-950 Lublin, Poland E-mail: potembskaemilia@gmail.com

Received: 26.07.2017; accepted: 02.01.2018; first published: 21.02.2018 symptoms and another $6 \%$ - symptoms of an eating disorder. Bernardi and Pallanti [13] have found that addiction to the Internet is co-morbid with anxiety disorders (15\%), social phobia (15\%), dysthymia (7\%), obsessive-compulsive disorder (7\%) and traits of avoidant personality disorder (7\%) and borderline personality disorder (14\%).

Yang et al. [3] and Yen et al. [14] have observed that adolescents addicted to the Internet are more likely than their non-addicted peers to suffer from somatization, obsessivecompulsive, anxiety and depressive disorders and exhibit social phobia and hostility. Yang [2] has shown that $13 \%$ of Internet dependent adolescents are diagnosed with obsessivecompulsive disorder, $9 \%$ have somatization disorder and 8.7\% suffer from anxiety disorder.

In the opinion of Alavi et al. [15] and Alizadeh-Sahraee et al. [16], Internet addiction co-occurs with increased symptoms of depression, anxiety, somatization disorder and phobia. According to Dong et al. [17], obsessive-compulsive disorder precedes the emergence of Internet dependence in adolescents, while depression, anxiety and hostility are some of the consequences of this dependence.

Numerous researchers [15, 18-26] describe relationships between the severity of symptoms of addiction to the Internet and to video games in adolescents, on the one hand, and 
symptoms of anxiety and depression, on the other. Yen et al. [14] have demonstrated in a study of 3,662 adolescents that the likelihood of joining the group of Internet addicts is increased by higher social anxiety and depression.

Zboralski et al. [5] found that the higher the severity of anxiety in the adolescents surveyed with the Spielberger StateTrait Anxiety Inventory (STAI), the more severe were their symptoms of Internet addiction. Liu and Kuo [27], Harman et al. [28] and Shepherd and Edelmann [29] suggest that Internet dependent adolescents show more severe symptoms of social phobia than non-addicted individuals.

The results cited in the literature [4, 30-37] show that young people addicted to the Internet have significantly increased symptoms of depression, compared to non-addicted individuals. Similar conclusions have been formulated by Lam et al. [9], who reported that young people aged 13-18 years, dependent on the Internet, showed a significantly higher severity of depressive symptoms than their nonaddicted peers. Tsitsika et al. [38] found that depression is 4 times more common in young people addicted to the Internet than in non-addicts.

Leung [39] points out that adolescents with severe depressive symptoms are more likely to escape into virtual reality than non-addicted youths. According to Jang et al. [10], both depression and obsessive-compulsive symptoms increase the risk of Internet addiction; similarly, Yen et al. [4] believe that increased depression is a risk factor for Internet addiction. According to Huang et al. [40], 25\% of people addicted to the Internet are diagnosed with depression, which is the strongest predictor of the development of Internet addiction. Ko et al. [41] mention the following factors which predispose young people to developing Internet addiction in boys and girls: depression, social phobia and hostility alone in the former, and hostility alone in the latter. Desai et al. [42] believe that depression is a risk factor for Internet addiction in both boys and girls. Results obtained by Bakken et al. [43] indicate that people who are dependent on the Internet or are at risk of developing the dependency more often report depression, suicidal thoughts, anxiety and obsessive-compulsive disturbances than people who are not addicted to the Internet.

The presented study investigates the question whether gender and place of residence have an impact on the development of psychopathological symptoms in individuals at risk and not at risk of Internet addiction, and what that impact might be. To the best of the authgors' knowledge, this problem had not been studied previously.

\section{OBJECTIVE}

The aim of this study was to compare the severity of psychopathological symptoms in individuals at risk of Internet addiction (according to Young's criteria) and those not at risk of developing this addiction. For the analyses, the participants were divided into groups according to gender and place of residence.

\section{MATERIALS AND METHOD}

A group of 692 respondents (485 females and 207 males) aged 18-25 years was studied. The average age of the participants was 20.8 years. $56.06 \%$ of the individuals taking part in the study were urban dwellers and $43.94 \%$ resided in rural areas. Among the young adults who lived in urban areas $31.63 \%$ were males and $68.37 \%$ were females. In the group of rural respondents, $31.04 \%$ were males and $68.96 \%$ were females.

The following research methods were used in this study: 1. A sociodemographic questionnaire designed by the authors.

2. Young's 20-item Internet Addiction Test (IAT), Polish translation by Majchrzak and Ogińska-Bulik [44].

3. The "O" Symptom Checklist designed by Aleksandrowicz.

The latter is a derivative/modification of SCL-90-R. The Checklist is made up of scales corresponding to the following 14 types of disorders: dysthymic disorder, phobic anxiety disorder, other anxiety disorders, obsessive-compulsive disorder, hypochondriacal disorder, neurasthenia, depersonalisation-derealisation, inorganic sleep disorders and sexual dysfunctions. Scale 10 describes avoidant and dependent personality traits, while scale 11 describes a personality with elements of impulsive-type emotional instability (borderline) and histrionic traits [45-47].

In order to compare the variables determined on the interval scale (severity of pathological symptoms), a Student's t test was used. Relationships between the severity of psychopathological symptoms and the selected sociodemographic variables were calculated on the basis of the point-biserial correlation coefficient. A p value of 0.05 was deemed statistically significant. STATISTICA version 10.0 (StatSoft, PL) was used to prepare the database and perform the statistical analyses.

\section{RESULTS}

In the first stage of the study, Internet addiction was assessed using Young's IAT. Of the 692 participants, 273 were found to be at risk of Internet addiction, with an IAT score of over 40 points, and 419 , who scored less than 40 points on the IAT scale, and were not at risk of developing the addiction (control group). In the at-risk group, there were 181 females and 92 males, and in the control group there were 304 females and 115 males. Table 1 shows a Student's t-test comparison of scores on the "O" Symptom Checklist scales obtained by the participants at risk of Internet addiction, and those not at risk.

Persons at risk of Internet addiction, both considered as a whole group and segregated by gender, obtained significantly higher scores on all scales of the "O" Symptom Checklist, compared to the control group. Young people at risk of Internet addiction were characterized by a significantly higher severity of symptoms of obsessive-compulsive, conversion and anxiety disorders, autonomic dysfunctions of the heart and the cardiovascular system, somatization and hypochondriacal disorders, neurasthenia, and dysthymia. The at-risk participants showed higher levels of impulsivity and had more pronounced avoidant and dependent personality traits. Table 2 shows the results of Student's t-test which compares the severity of psychopathological symptoms between individuals (males and females) at risk of Internet addiction - urban and rural inhabitants.

Persons at risk of Internet addiction who live in rural areas has significantly more severe psychopathological_symptoms, 
Table 1. Comparison of severity of psychopathological symptoms in individuals at risk and those not at risk of Internet addiction

\begin{tabular}{|c|c|c|c|c|c|c|}
\hline \multirow{3}{*}{ "O" Symptom Checklist Scales } & \multicolumn{6}{|c|}{ Entire group } \\
\hline & \multicolumn{2}{|c|}{ Not at risk of addiction } & \multicolumn{2}{|c|}{ At risk of addiction } & \multirow{2}{*}{$\mathbf{t}$} & \multirow{2}{*}{$\mathbf{p}$} \\
\hline & M & SD & M & SD & & \\
\hline Phobic disorder & 0.50 & 0.72 & 1.02 & 1.18 & -7.27 & 0.001 \\
\hline Anxiety disorder & 1.21 & 1.18 & 1.92 & 1.56 & -6.76 & 0.001 \\
\hline Obsessive-compulsive disorder & 0.82 & 0.97 & 1.58 & 1.39 & -8.47 & 0.001 \\
\hline Autonomic dysfunctions of heart and cardiovascular system & 1.16 & 1.10 & 1.81 & 1.51 & -5.99 & 0.001 \\
\hline Somatization disorder & 0.73 & 0.76 & 1.21 & 1.21 & -5.91 & 0.001 \\
\hline Hypochondriacal disorder & 0.67 & 1.10 & 1.33 & 1.56 & -6.54 & 0.001 \\
\hline Neurasthenia & 1.58 & 1.27 & 2.35 & 1.60 & -6.96 & 0.001 \\
\hline Depersonalisation-derealisation syndrome & 1.01 & 1.13 & 1.68 & 1.50 & -6.12 & 0.001 \\
\hline Personality disorder: avoidance and dependence & 1.22 & 1.31 & 2.11 & 1.67 & -7.23 & 0.001 \\
\hline Inorganic sleep disorder & 1.41 & 1.60 & 1.91 & 1.73 & -3.61 & 0.001 \\
\hline Sexual dysfunction & 0.38 & 0.79 & 0.86 & 1.23 & -5.80 & 0.001 \\
\hline Dysthymia & 1.41 & 1.29 & 2.20 & 1.61 & -7.10 & 0.001 \\
\hline Global score & 123.13 & 92.29 & 189.63 & 159.19 & -4.54 & 0.001 \\
\hline
\end{tabular}

Men

\begin{tabular}{|c|c|c|c|c|c|c|}
\hline \multirow{2}{*}{ "O" Symptom Checklist Scales } & \multicolumn{2}{|c|}{ Not at risk of Internet addiction } & \multicolumn{2}{|c|}{ At risk of Internet addiction } & \multirow{2}{*}{$\mathbf{t}$} & \multirow{2}{*}{$\mathbf{p}$} \\
\hline & M & SD & M & SD & & \\
\hline Phobic disorder & 0.38 & 0.59 & 0.71 & 1.03 & -2.96 & 0.003 \\
\hline Obsessive-compulsive disorder & 0.78 & 1.00 & 1.38 & 1.34 & -3.71 & 0.001 \\
\hline Conversions and dissociations & 0.42 & 0.55 & 0.90 & 1.14 & -3.99 & 0.001 \\
\hline Autonomic dysfunctions of heart and cardiovascular system & 0.70 & 0.77 & 1.35 & 1.32 & -4.12 & 0.001 \\
\hline Somatization disorder & 0.56 & 0.56 & 0.90 & 1.05 & -2.80 & 0.006 \\
\hline Hypochondriacal disorder & 0.57 & 0.99 & 0.98 & 1.43 & -2.41 & 0.017 \\
\hline Neurasthenia & 1.18 & 1.05 & 1.88 & 1.41 & -4.07 & 0.001 \\
\hline Depersonalisation-derealisation syndrome & 0.73 & 0.98 & 1.30 & 1.34 & -3.31 & 0.001 \\
\hline Personality disorder: avoidance and dependence & 0.79 & 0.98 & 1.69 & 1.48 & -4.84 & 0.001 \\
\hline Personality disorder: impulsivity and histrionism & 0.79 & 1.05 & 1.24 & 1.45 & -2.36 & 0.020 \\
\hline Sexual dysfunction & 0.44 & 0.91 & 0.65 & 0.98 & -1.54 & 0.126 \\
\hline Dysthymia & 0.96 & 1.11 & 1.86 & 1.47 & -5.05 & 0.001 \\
\hline Global score & 89.00 & 67.16 & 130.37 & 104.62 & -2.13 & 0.036 \\
\hline \multicolumn{7}{|c|}{ Women } \\
\hline \multirow{2}{*}{ “O” Symptom Checklist Scales } & \multicolumn{2}{|c|}{ Not at risk of Internet addiction } & \multicolumn{2}{|c|}{ At risk of Internet addiction } & \multirow{2}{*}{$\mathbf{t}$} & \multirow{2}{*}{$\mathbf{P}$} \\
\hline & M & SD & M & SD & & \\
\hline Phobic disorder & 0.54 & 0.76 & 1.18 & 1.22 & -7.07 & 0.001 \\
\hline Anxiety disorder & 1.38 & 1.24 & 2.15 & 1.60 & -5.93 & 0.001 \\
\hline Obsessive-compulsive disorder & 0.84 & 0.96 & 1.69 & 1.41 & -7.85 & 0.001 \\
\hline Conversions and dissociations & 0.65 & 0.83 & 1.28 & 1.36 & -6.39 & 0.001 \\
\hline Autonomic dysfunctions of heart and cardiovascular system & 1.35 & 1.16 & 2.03 & 1.55 & -5.01 & 0.001 \\
\hline Somatization disorder & 0.80 & 0.82 & 1.36 & 1.25 & -5.43 & 0.001 \\
\hline Neurasthenia & 1.74 & 1.31 & 2.58 & 1.64 & -6.26 & 0.001 \\
\hline Depersonalisation-derealisation syndrome & 1.13 & 1.17 & 1.85 & 1.55 & -5.39 & 0.001 \\
\hline Personality disorder: avoidance and dependence & 1.39 & 1.39 & 2.31 & 1.72 & -5.93 & 0.001 \\
\hline Personality disorder: impulsivity and histrionism & 1.38 & 1.33 & 2.24 & 1.70 & -5.73 & 0.001 \\
\hline Inorganic sleep disorder & 1.56 & 1.68 & 2.13 & 1.81 & -3.27 & 0.001 \\
\hline Sexual dysfunction & 0.35 & 0.74 & 0.96 & 1.32 & -5.93 & 0.001 \\
\hline Dysthymia & 1.58 & 1.31 & 2.37 & 1.66 & -5.77 & 0.001 \\
\hline Global score & 133.65 & 96.55 & 219.26 & 173.49 & -4.65 & 0.001 \\
\hline
\end{tabular}


Table 2. Comparison of severity of psychopathological symptoms in adolescents at risk of Internet addiction living in urban and rural areas

\begin{tabular}{|c|c|c|c|c|c|c|}
\hline \multicolumn{7}{|c|}{ Persons at risk of Internet addiction } \\
\hline \multirow{2}{*}{ “O” Symptom Checklist Scales } & \multicolumn{2}{|c|}{ Urban } & \multicolumn{2}{|c|}{ Rural } & \multirow{2}{*}{$t$} & \multirow{2}{*}{$\mathbf{p}$} \\
\hline & M & SD & M & SD & & \\
\hline Phobic disorder & 0.86 & 1.12 & 1.24 & 1.20 & -2.70 & 0.007 \\
\hline Anxiety disorder & 1.79 & 1.51 & 2.09 & 1.59 & -1.61 & 0.109 \\
\hline Obsessive-compulsive disorder & 1.38 & 1.32 & 1.85 & 1.43 & -2.75 & 0.006 \\
\hline Conversions and dissociations & 0.99 & 1.27 & 1.37 & 1.31 & -2.39 & 0.017 \\
\hline Autonomic dysfunctions of heart and cardiovascular system & 1.60 & 1.53 & 2.09 & 1.42 & -2.48 & 0.014 \\
\hline Somatization disorder & 1.06 & 1.12 & 1.41 & 1.29 & -2.24 & 0.026 \\
\hline Hypochondriacal disorder & 1.14 & 1.41 & 1.59 & 1.72 & -2.40 & 0.017 \\
\hline Neurasthenia & 2.29 & 1.62 & 2.42 & 1.58 & -0.65 & 0.519 \\
\hline Depersonalisation-derealisation syndrome & 1.54 & 1.51 & 1.85 & 1.45 & -1.59 & 0.113 \\
\hline Personality disorder: avoidance and dependence & 1.94 & 1.68 & 2.32 & 1.64 & -1.74 & 0.084 \\
\hline Personality disorder: impulsivity and histrionism & 1.75 & 1.67 & 2.16 & 1.68 & -1.87 & 0.062 \\
\hline Inorganic sleep disorder & 1.68 & 1.73 & 2.23 & 1.67 & -2.44 & 0.015 \\
\hline Sexual dysfunction & 0.83 & 1.18 & 0.91 & 1.29 & -0.48 & 0.629 \\
\hline Dysthymia & 2.07 & 1.68 & 2.39 & 1.52 & -1.61 & 0.109 \\
\hline Global score & 160.39 & 140.47 & 243.87 & 173.58 & -2.82 & 0.006 \\
\hline
\end{tabular}

\begin{tabular}{|c|c|c|c|c|c|c|}
\hline Global score & 160.39 & 140.47 & 243.87 & 173.58 & -2.82 & 0.006 \\
\hline & isk of Int & diction & & & & \\
\hline "Q" sumntom Chollit solo & & & & & $t$ & $\mathbf{P}$ \\
\hline 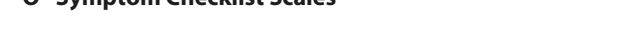 & M & SD & M & SD & ( & $r$ \\
\hline Phobic disorder & 0.52 & 0.75 & 0.97 & 1.25 & -2.14 & 0.035 \\
\hline Anxiety disorder & 1.24 & 1.22 & 1.76 & 1.50 & -1.82 & 0.072 \\
\hline Obsessive-compulsive disorder & 1.13 & 1.15 & 1.72 & 1.51 & -2.13 & 0.036 \\
\hline Conversions and dissociations & 0.66 & 0.84 & 1.22 & 1.38 & -2.38 & 0.019 \\
\hline Autonomic dysfunctions of heart and cardiovascular system & 1.03 & 1.11 & 1.77 & 1.45 & -2.52 & 0.014 \\
\hline Somatization disorder & 0.68 & 0.81 & 1.16 & 1.26 & -1.99 & 0.050 \\
\hline Hypochondriacal disorder & 0.75 & 1.16 & 1.26 & 1.68 & -1.73 & 0.088 \\
\hline Neurasthenia & 1.82 & 1.39 & 1.98 & 1.46 & -0.52 & 0.606 \\
\hline Depersonalisation-derealisation syndrome & 1.08 & 1.13 & 1.61 & 1.52 & -1.77 & 0.080 \\
\hline Personality disorder: avoidance and dependence & 1.51 & 1.48 & 1.91 & 1.48 & -1.18 & 0.242 \\
\hline Personality disorder: impulsivity and histrionism & 1.11 & 1.40 & 1.43 & 1.51 & -0.96 & 0.343 \\
\hline Inorganic sleep disorder & 1.03 & 1.21 & 1.99 & 1.57 & -3.02 & 0.003 \\
\hline Sexual dysfunction & 0.46 & 0.75 & 0.90 & 1.17 & -2.01 & 0.048 \\
\hline Dysthymia & 1.70 & 1.50 & 2.08 & 1.43 & -1.24 & 0.220 \\
\hline Global score & 120.45 & 107.47 & 161.10 & 93.56 & -1.07 & 0.291 \\
\hline & t risk of I & ddiction & & & & \\
\hline “O” Cumntom Chollict Scals & & & & & $\star$ & D \\
\hline 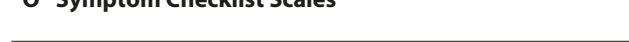 & M & SD & M & SD & I & $r$ \\
\hline Phobic disorder & 1.01 & 1.22 & 1.40 & 1.15 & -2.09 & 0.038 \\
\hline Anxiety disorder & 2.04 & 1.57 & 2.29 & 1.62 & -1.02 & 0.310 \\
\hline Obsessive-compulsive disorder & 1.50 & 1.38 & 1.92 & 1.39 & -1.98 & 0.049 \\
\hline Conversions and dissociations & 1.15 & 1.40 & 1.46 & 1.26 & -1.52 & 0.130 \\
\hline Autonomic dysfunctions of heart and cardiovascular system & 1.85 & 1.62 & 2.26 & 1.39 & -1.68 & 0.095 \\
\hline Somatization disorder & 1.22 & 1.20 & 1.54 & 1.30 & -1.65 & 0.101 \\
\hline Hypochondriacal disorder & 1.31 & 1.48 & 1.78 & 1.72 & -1.94 & 0.054 \\
\hline Neurasthenia & 2.51 & 1.69 & 2.67 & 1.60 & -0.66 & 0.512 \\
\hline Depersonalisation-derealisation syndrome & 1.74 & 1.61 & 1.98 & 1.41 & -0.98 & 0.329 \\
\hline Personality disorder: avoidance and dependence & 2.13 & 1.73 & 2.54 & 1.69 & -1.51 & 0.132 \\
\hline Personality disorder: impulsivity and histrionism & 2.02 & 1.71 & 2.55 & 1.64 & -1.98 & 0.049 \\
\hline Inorganic sleep disorder & 1.96 & 1.84 & 2.36 & 1.72 & -1.39 & 0.167 \\
\hline Sexual dysfunction & 0.98 & 1.30 & 0.91 & 1.36 & 0.36 & 0.719 \\
\hline Dysthymia & 2.24 & 1.73 & 2.57 & 1.55 & -1.29 & 0.200 \\
\hline Global score & 183.75 & 152.73 & 273.43 & 186.89 & -2.32 & 0.023 \\
\hline
\end{tabular}


including obsessive-compulsive, conversion, autonomic, somatization, hypochondriac and phobic symptoms, compared to their urban peers. Rural dwellers at risk of addiction to the Internet were more impulsive than "at-risk" urban residents.

Males at risk of Internet addiction who live in rural areas were more likely to complain of symptoms of phobia, obsessive-compulsive disorder, autonomic dysfunctions, and somatization disorder, as well as symptoms of inorganic sleep disorder and sexual dysfunctions, compared to urban males.

Females living in rural areas at risk of Internet addiction were significantly more likely than their peers living in urban areas to experience severe neurotic disorders, mainly phobias and obsessive-compulsive and hypochondriac disorders. At-risk females living in rural areas were significantly more impulsive than those living in urban areas.

\section{DISCUSSION}

The results obtained in the presented study indicate that individuals who meet Young's criteria for risk of Internet addiction, compared to those who do not meet those criteria, have significantly higher pathological scores, mainly with regard to symptoms of obsessive-compulsive, conversion and anxiety disorders, autonomic dysfunctions of the heart and the cardiovascular system, somatization (somatic symptom) and hypochondriac disorders, neurasthenia and depression. Differences in the severity of these psychopathological symptoms occurred both in the groups of females and males.

The results obtained are consistent with the findings that pathological Internet use is co-morbid with increased symptoms of anxiety disorder [48, 49], depression [12] and obsessive-compulsive disorder [1,13]. Yang et al. [2,3] and Yen et al. [14] have observed the presence of somatization disorders in adolescents addicted to the Internet. Relationships between Internet addiction and increased symptoms of depression, anxiety, phobias and somatization disorders have also been described by Alavi et al. [15] and Alizadeh-Sahraee et al. [16] While some authors believe that symptoms of obsessivecompulsive disorder are predictors of Internet addiction in adolescents, and anxiety and depression are some of its consequences [17], others consider depression [4, 8, 40-42, 50-52] and obsessive-compulsive disorder [10] to be risk factors for the development of the addiction. Tsitsika et al. [38] have pointed out that depression is 4 times more common in young people addicted to the Internet than in their nonaddicted peers.

In the presented study, it was also found that individuals at risk of Internet addiction are more impulsive and have more pronounced traits of avoidant and dependent personality. A similar observation has been made by Armstrong et al. [53], who believe that impulsivity and low self-esteem are the strongest predictors of the development of Internet addiction in adolescents. Canan et al. [54] and Yeon [55] emphasis that individuals addicted to the Internet are submissive and have traits of avoidant personality disorder. Bernardi and Pallanti [13] have also described avoidant personality traits in people addicted to the Internet.

To summarize the results of the current study, psychopathological symptoms can be both a cause and an effect of the abnormal behaviour related to young people's online activity and can also sustain such behaviour. According to Yen et al. [14], psychopathological symptoms and Internet addiction can exacerbate each other via a feedback loop, with a role played by gender and place of residence, as shown by the results obtained in thpresented study. Awareness of the existence of all these relationships can be of assistance to practitioners who treat people addicted to the Internet and those at risk of addiction.

\section{CONCLUSIONS}

1. Individuals at risk of Internet addiction are characterized by a significantly higher severity of pathological symptoms, chiefly obsessive-compulsive, conversion, anxiety, and depressive symptoms.

2. Persons at risk of Internet addiction who live in rural areas have significantly more severe symptoms of neurotic disorders, mainly obsessive-compulsive, hypochondriac and phobic symptoms, compared to their urban peers.

\section{REFERENCES}

1. Xiuqin H, Huimin Z, Mengchen L, Jinan W, Ying Z, Ran T. Mental health, personality, and parental rearing styles of adolescents with Internet addiction disorder. Cyberpsychol Behav Soc Netw. 2010; 13(4): 401-406.

2. Yang CK. Sociopsychiatric characteristics of adolescents who use computers to excess. Acta Psychiatr Scand. 2001; 104(3), 217-222.

3. Yang CK, Choe BM, Baity M, Lee JH, Cho JS. SCL-90-R and 16PF profiles of senior high school students with excessive internet use. Can J Psychiatry. 2005; 50(7): 407-414.

4. Yen JY, Ko CH, Yen CF, Lee JH, Cho JS. The comorbid psychiatric symptoms of Internet addiction: attention deficit and hyperactivity disorder (ADHD), depression, social phobia, and hostility. J Adolesc Health. 2007; 41(1): 93-98.

5. Zboralski K, Orzechowska A, Talarowska M, et al. The prevalence of computer and Internet addiction among pupils. Postepy Hig Med Dosw. 2009; 63: 8-12.

6. Park S. The association between Internet use and depressive symptoms among South Korean adolescents. J Spec Ped Nurs. 2009; 14(4): 230-238.

7. Morgan C, Cotten SR. The relationship between Internet activities and depressive symptoms in a sample of college freshmen. Cyberpsychol Behav Soc Netw. 2003; 6(2): 133-142.

8. Morrison CM, Gore H. The relationship between excessive Internet use and depression: A questionnaire-based study of 1,319 young people and adults. Psychopathology. 2010; 43(2): 121-126.

9. Lam LT, Peng ZW, Mai JC, Jing J. Factors associated with Internet addiction among adolescents. Cyberpsychol Behav. 2009; 12(5): 551-555.

10. Jang KS, Hwang SY, Choi JY. Internet addiction and psychiatric symptoms among Korean adolescents. J School Health. 2008; 78(3): $165-171$.

11. Ha JH, Kim SY, Bae SC, et al. Depression and Internet addiction in adolescents. Psychopathology. 2007; 40(6): 424-430.

12. Chele GE, Jijie C, Chirita R, Stefanescu C. Management of internet addiction with comorbid psychiatric condition in Romanian childrens. Eur Psychiatry. 2011; 26 (Suppl.1): 272.

13. Bernardi S, Pallanti S. Internet addiction: a descriptive clinical study focusing on comorbidities and dissociative symptoms. Compr Psychiatry. 2009; 50(6): 510-516.

14. Yen JY, Ko CH, Yen CF, Chen SH, Chung WL, Chen CC. Psychiatric symptoms in adolescents with Internet addiction: Comparison with substance use. Psychiatry Clin Neurosci. 2008; 62(1): 9-16.

15. Alavi SS, Maracy MR, Jannatifard F, Eslami M. The effect of psychiatric symptoms on the internet addiction disorder in Isfahan's university students. J Res Med Sci. 2011; 16(6): 793-800.

16. Alizadeh-Sahraee O, Khosravi Z, Yusefnejad M. The relationship of internet addiction with family functioning and mental health among Iranian students. Eur Psychiatry. 2011; 26(1): 1822-1822.

17. Dong G, Lu Q, Zhou H, Zhao X. Precursor or sequela: pathological disorders in people with Internet addiction disorder. PLoS One. 2011; 6(2), e14703. doi:10.1371/ journal.pone.0014703. 
18. Ammerschläger M, Müller K, Wölfling K. Prevalence rate and comorbidity of computer addiction of children in a German psychiatry. Eur Psychiatry. 2010; 25(Suppl.1): 53.

19. Munteanu A, Costea I, Palos R, Jinaru A. Psychological and behavior aspects regarding Internet addiction. Annals of DAAAM International. 2009; 20(1): 1477-1478.

20. Peukert P, Sieslack S, Barth G, Batra A. Internet- und Computerspielabhängigkeit Phänomenologie, Komorbidität, Ätiologie, Diagnostik und Therapeutische Implikationen für Betroffene und Angehörige. Psychiatr Prax. 2010; 37(5): 219-224.

21. Pan JY, Zhang JH, Ma P, Liang HJ, Yang LX. Personality characteristics and psychiatric symptoms in senior university students with internet addiction disorder. Chin J Clin Rehabil. 2006; 10(18): 56-58.

22. Park K, Kim MH, Jun HC. Psychiatric variables (alcohol and internet use behavior, anxiety, depression) and academic achievement in premedical students in a Korean university. Eur Child Adol Psychiatry. 2011; 20(Suppl.1): S182.

23. Spada MM, Langston B, Nikcevic AV, Moneta GB. The role of metacognitions in problematic internet use. Computers in Human Behavior, 2008; 24(5): 2325-2335.

24. Sebeyran A, Hassler C, Choquet M, et al. Anxiety and depression in non-treatment-seeking subjects with Internet addiction. European Neuropsychopharmacology. 2011; 21(Suppl.1): S596.

25. Tahiroğlu AY, Çelik GG, Fettahoğlu Ç, et al. Problematic Internet use in the psychiatric sample compared community sample. Arch Neuropsychiatry. 2010; 47(3): 241-246.

26. Te Wildt BT, Putzig I, Vukicevic A, Wedegartner F. Storungen von selbsterleben und beziehungsverhalten bei menschen mit internetabhangigkeit. Sucht. 2011; 57(1): 17-26.

27. Liu CY, Kuo FY. A study of Internet addiction through the lens of the Interpersonal Theory. Cyberpsychol Behav. 2007; 10(6): 799-804.

28. Harman JP, Hansen CE, Cochran ME, Lindsey CR. Liar, liar: internet faking but not frequency of use affects social skills, self-esteem, social anxiety, and aggression. Cyberpsychol Behav. 2005; 8(1): 1-6.

29. Shepherd RM, Edelmann RJ. Reasons for internet use and social anxiety. Personality and Individual Differences. 2005; 39(5): 949-958.

30. Liu TC, Desai RA, Krishnan-Sarin S, Cavallo DA, Potenza MN. Problematic internet use and health in adolescents: data from a high school survey in Connecticut. J Clin Psychiatry. 2011; 72(6): 836-845.

31. Mythily S, Qiu S, Winslow M. Prevalence and correlates of excessive Internet use among youth in Singapore. Ann Acad Med Singapore. 2008; 37(1): 9-14.

32. Ni X, Yan H, Chen S, Liu Z. Factors influencing internet addiction in a sample of freshmen university students in China. Cyberpsychol Behav. 2009; 12(3): 327-330.

33. Stojakovic M. Depression and Internet addiction: correlation and treatment approaches. Eur Psychiatry. 2011; 26(Suppl.1): 2195-2195.

34. Frangos CC. Internet dependence in college students from Greece. Eur Psychiatry. 2009; 24(Suppl.1): S419.

35 . Young KS, Rogers RC. The relationship between depression and Internet addiction. Cyberpsychol Behav. 1998; 1(1): 25-28.

36. Özcan NK, Buzlu S. Internet use and its relation with the psychosocial situation for a sample of university students. Cyberpsychol Behav. 2007; 10(6): 767-772.
37. Te Wildt BT, Putzig I, Zedler M, Ohlmeier MD. Internetabhängigkeit als ein Symptom depressiver Störungen. Psychiatr Prax. 2007; 34(Supp.3): 318-322.

38. Tsitsika A, Critselis E, Louizou A, et al. Determinants of Internet addiction among adolescents: A Case-control study. Scientific World Journal. 2011; 11, 866-874.

39. Leung L. Net-generation attributes and seductive properties of the Internet as predictors of online activities and Internet addiction. Cyberpsychol Behav. 2004; 7(3): 333-348.

40. Huang RL, Lu Z, Liu JJ, et al. Features and predictors of problematic internet use in Chinese college students. Behav Info Technol. 2009; 28(5): 485-490.

41. Ko CH, Yen JY, Chen CS, Yeh YC, Yen CF. Predictive values of psychiatric symptoms for internet addiction in adolescents: a 2-year prospective study. Arch Pediatr Adolesc Med. 2009; 163(10): 937-943.

42. Desai RA, Krishnan-Sarin S, Cavallo D. Potenza MN. Video-gaming among high school students: health correlates, gender differences, and problematic gaming. Pediatrics. 2010; 126(6): 1414-1424.

43. Bakken IJ, Wenzel HG, Götestam KG, Johansson A, Øren A. Internet addiction among Norwegian adults: a stratified probability sample study. Scand J Psychol. 2009; 50(2): 121-127.

44. Majchrzak P, Ogińska-Bulik N. Zachowania ryzykowne związane z cyberprzestrzenią - polska adaptacja Internet Addiction Test. In: Ogińska-Bulik N. (ed.): Zachowania ryzykowne dzieci i młodzieży. Łódź: Wydawnictwo WSHE; 2006. p. 59-78 (in Polish).

45. Rewer A. Skale kwestionariusza objawowego „O”. Psychiatr Pol. 2000; 34(6): 931-943 (in Polish).

46. Aleksandrowicz JW, Hamuda G. Kwestionariusze objawowe w diagnozie i w badaniach epidemiologicznych zaburzeń nerwicowych. Psychiatr Pol. 1994; 28(6): 667-676 (in Polish).

47. Aleksandrowicz JW. Kwestionariusz objawowy SII. Psychiatr Pol. 2000; 34(6): 945-959 (in Polish).

48. Cao F, Su L. Internet addiction among Chinese adolescents: prevalence and psychological features. Child Care Health Dev. 2007; 33(3): 275-281.

49. Meixner S. Stress und Sucht im Internet. Vortrag gehalten auf der 4. Grazer Psychiatrisch-Psychosomatischen Tagung vom 2009 Januar 22.-24; Graz, Germany

50. Caplan SE. Preference for online social interaction. A theory of problematic Internet use and psychosocial well-being. Communication Research. 2003; 30(6): 625-648.

51. Ceyhan AA, Ceyhan E. Loneliness, depression, and computer selfefficacy as predictors of problematic internet use. Cyberpsychol Behav. 2008; 11(6): 699-701.

52. Oh WO. Factors influencing internet addiction tendency among middle school students in Gyeong-buk area. Taehan Kanho Hakhoe Chi. 2003; 33(8): 1135-1144.

53. Armstrong L, Phillips JG, Saling LL. Potential determinants of heavier internet usage. Int J Hum Comput St. 2000; 53: 537-550.

54. Canan F, Ataoglu A, Nichols LA. Evaluation of psychometric properties of the Internet addiction scale in a sample of Turkish high school students. Cyberpsychol Behav Soc Netw. 2010; 13(3): 317-320.

55 . Yeon B. A study of the relationship between Internet addiction tendency and personality disorders. J Cancer Edu. 2009; 24(Suppl.1): S673-S674. 